\title{
AN UNUSUAL MASS OF THE CHEST WALL IN A 7-YEAR-OLD CHILD: AN ASKIN'S TUMOUR
}

\author{
Imran Hashim, Nabila Talat, Jamal Butt, Muhammad Saleem, Ghazala Hanif \\ Department of Paediatric Surgery, The Children's Hospital and The Institute of Child Health, Lahore, Pakistan \\ Received: 9 February 2017 / Accepted: 15 October 2017
}

\begin{abstract}
Askin's tumour is a primitive neuroectodermal tumour developing from the soft tissues of the chest wall. It is commonly misdiagnosed due to features similar to other round blue cell tumours. The approach for its diagnosis and treatment is complex and requires a multidisciplinary team. The recommended treatment is chemotherapy and surgical excision mainly. The prognosis is dependent on many factors. We managed a child of Askin's tumour using modalities such as neoadjuvant chemotherapy and surgical excision and found a good response.
\end{abstract}

Key words: Chest wall mass, Askin's tumour, Ewing sarcoma

\section{Introduction}

Literature showed that frequency of Ewing's sarcoma (ES) and primitive neuroectodermal tumours (PNETs) among childhood tumours is just $2 \%$. That is the reason during the age of infancy and childhood, ESs and PNETs considered to be very rare. ${ }^{[1]}$ Askin's tumour in childhood usually presents with common symptoms of upper respiratory tract infections. These are closely related neoplasms derived from the neural crest cells tumours. ${ }^{[2]}$ In 1979, Askin et al. separated PNETs originating from thoracopulmonary region and named Askin's tumour. They belong to the family of the small round blue cell tumours and have no specific clinical and pathologic features which make difficult to differentiate it from other tumours of their family. ${ }^{[3]}$ In general, prognosis of these tumours is poor. The index case showed good response to multimodality treatment and till now no signs and symptoms of recurrence. Furthermore, on searching literature, we found that to date, there are very few case reports from Pakistan.

\section{Case Report}

A 7-year-old boy presented to the oncology department with complaint of intermittent, dull and moderate-tosevere pain along with progressively increasing swelling on the left lower chest wall for 1 year.

Correspondence: Dr. Imran Hashim, Department of

Paediatric Surgery, The Children's Hospital and The Institute

of Child Health, Lahore.

Email: deardrimi2002@yahoo.com
Patient was initially managed as a case of pulmonary Tuberculosis for about 3 months with no response. On examination, there was about $20 \mathrm{~cm} \times 14 \mathrm{~cm}$ firm, nontender and non-fluctuant swelling on the left chest wall extending from $5^{\text {th }}$ to $9^{\text {th }}$ rib [Figure 1]. All other physical parameters and laboratories including alpha-fetoprotein and beta-human chorionic gonadotropin were within normal range. Abdominal ultrasound showed complex multiloculated mild-to-moderate effusion involving lateral chest wall with internal septations and underlying consolidation. On CT scan, $19.3 \mathrm{~cm} \times 12.7 \mathrm{~cm}$ sized cystic mass in the left hemithorax with displacement of mediastinum. The evidence of rib destruction was there, but there was no mediastinal lymphadenopathy or bone involvement [Figure 2]. An incisional biopsy of mass was done and proved out to be CD99-positive round blue cell tumour probably ES [Figure 3]. The patient underwent 6 cycles of chemotherapy (vincristine, ifosfamide, doxorubicin and etoposide). Post-chemotherapy scan depicted reduction in mass size to just $6.0 \mathrm{~cm} \times 2.6 \mathrm{~cm}$ located underneath the lower left ribs, inseparable from the left lateral hemidiaphragm involving inner lower chest and upper abdominal wall but no lung infiltration [Figure 4]. The case was discussed in tumour board; excision of tumour was planned. The left subcostal incision was made and tumour approached through transdiaphragmatic route as it was involving the underlying ribs and diaphragm. After opening the diaphragm, it was visible on undersurface of lower ribs and excision was done [Figures 5-7]. 


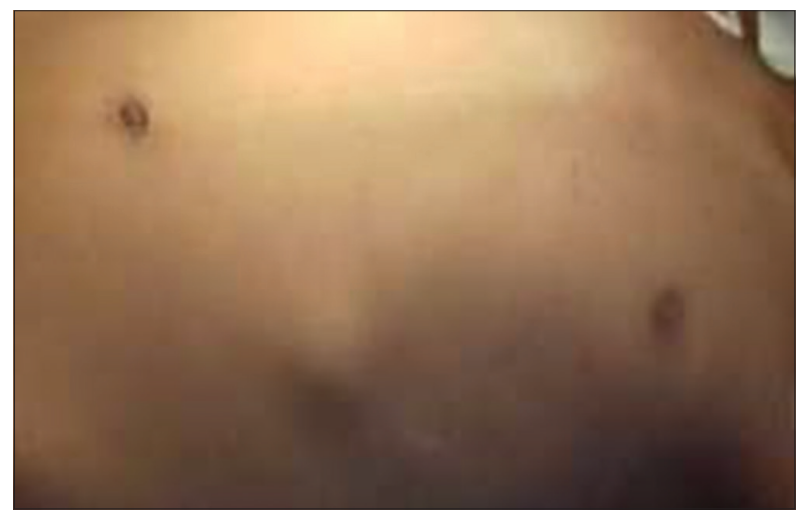

Figure 1: Anterior chest and abdomen picture

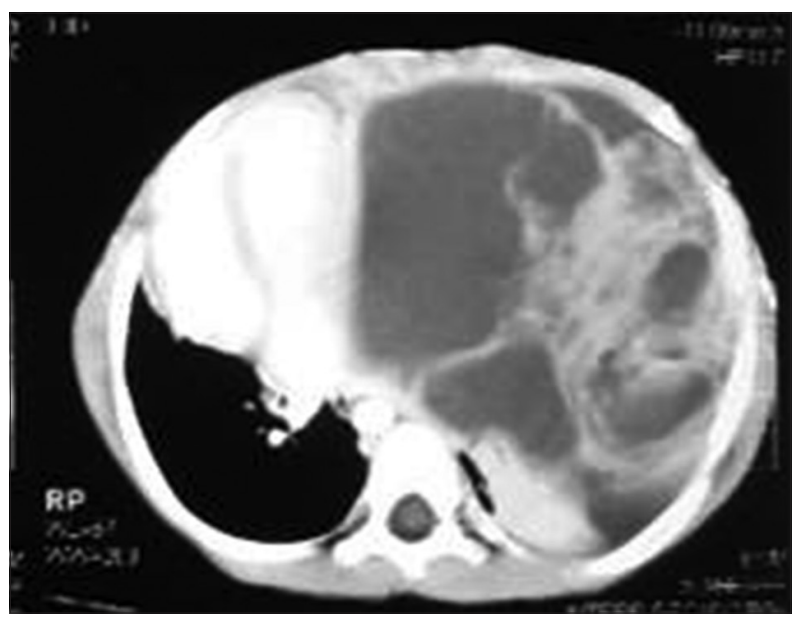

Figure 2: CT chest with contrast. The left chest wall (blue arrow) mass displacing the mediastinum

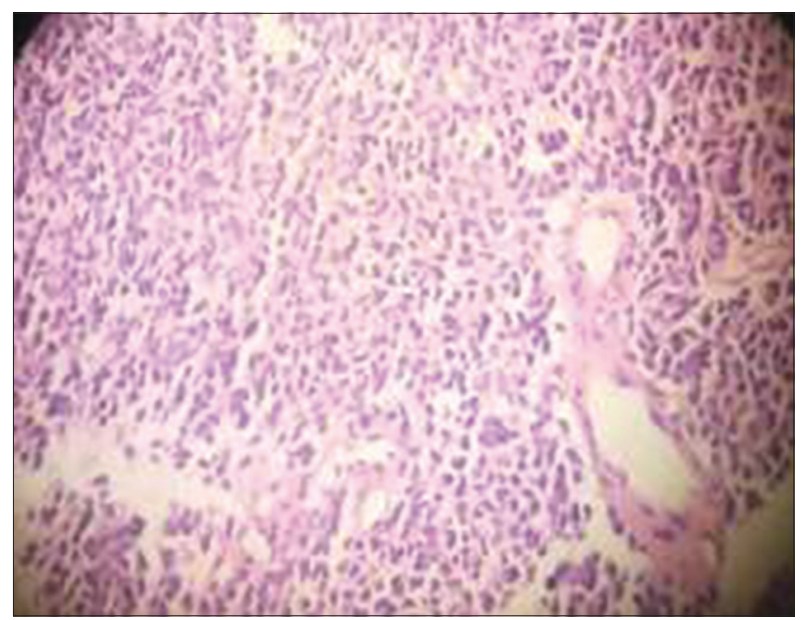

Figure 3: Round blue cell tumour ( $\mathrm{H}$ and $\mathrm{E})$

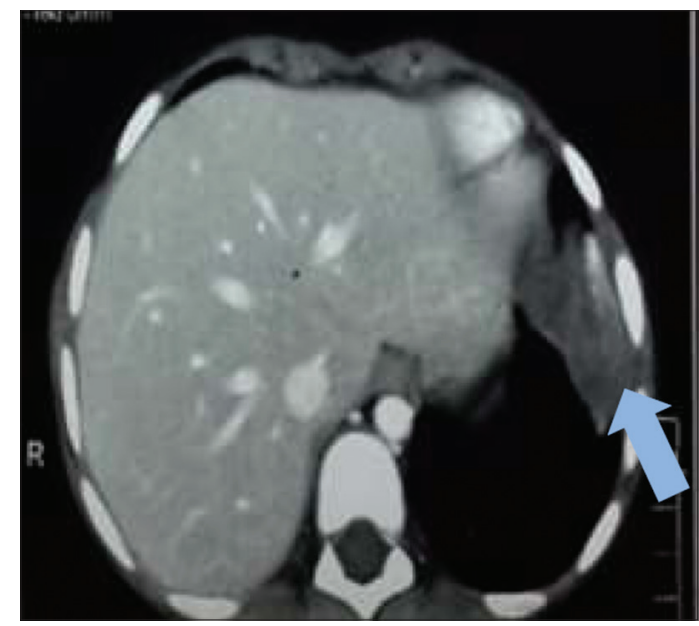

Figure 4: Post-chemotherapy CT scan showed a significant reduction in the left chest tumour mass

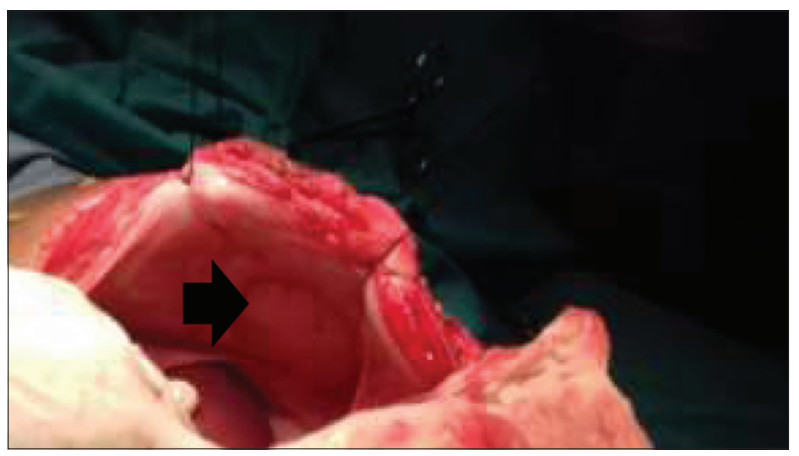

Figure 5: Residual tumour seen along the inside of chest wall (black solid arrow)

Peroperatively tumour was $5 \mathrm{~cm} \times 6 \mathrm{~cm}$ arising from the periosteum of lower ribs and attached to pleura of the left lower lobe and left hemidiaphragm. Periosteum was shaved and underlying rib surface was smooth. Biopsies were taken from pleural site, diaphragm and periosteum of rib. Closure of diaphragm and abdomen done [Figure 7]. Post-operative recovery of the patient was smooth and uneventful. He was initially shifted to intensive care unit and then general ward after 3 days. Chest tube was removed after 5 days. The patient was referred back to oncology ward. On histopathological examination of resected mass, there was no tumourous tissue and there was only fibrous tissue with necrosis. Furthermore, there was no residual tumour in pleura, diaphragm or rib periosteum. At 36 and 9 months' follow-up, the patient is doing fine and completed his post-operative chemotherapy. 


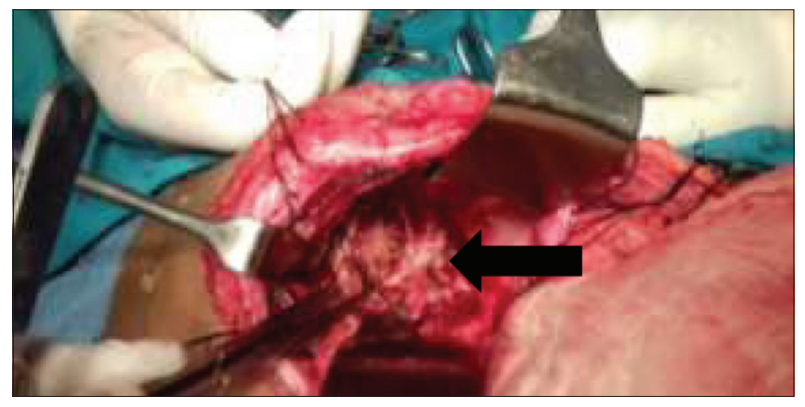

Figure 6: Residual tumours excised (black arrow)

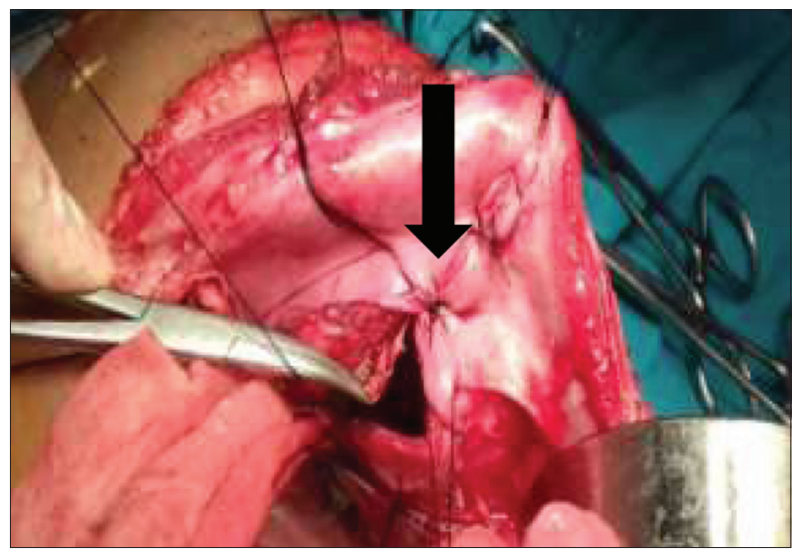

Figure 7: Repair of the diaphragm after excision of tumour (black arrow)

\section{Discussion}

PNETs, a group of highly malignant tumours, are of neuroectodermal origin that affects mainly soft tissue and bone. Due to indistinguishable clinical and pathologic features, Batsakis et al. divided the PNET family of tumours into the following three groups: Central nervous system PNETs, autonomic nervous system PNETs (neuroblastoma) and peripheral PNETs (pPNETs). ${ }^{[4]}$ The annual incidence of PNETs is 2.9 per million population with a slight male preponderance. Askin's tumour also named as "extra skeletal ES" or "soft tissue ES" arising from the soft tissue of the chest wall and usually present in the second decade of life. ${ }^{[5]}$ For extraosseous primary tumours, the most common primary sites of disease include the following: Trunk (32\%), extremities (26\%), head and neck (18\%) and retroperitoneum $(16 \%){ }^{\left[{ }^{[6]}\right.}$

Askin's tumour may present as a solitary mass, rarely involving most of the hemithorax or as multiple masses in the thoracopulmonary region (thoracic wall, lung, mediastinum or pericardium). Mostly, these tumours show a neural differentiation that can be demonstrated by immune histochemical and ultrastructural methods. Similar to ES and PNET, regarding immunohistochemistry, these tumours show positivity for neural markers such as neuron-specific enolase, CD99 and vimentin including neuroendocrine markers, such as chromogranin and synaptophysin. ${ }^{[7]}$

CD 99 was also positive in our index case. In the thoracic area, these tumours are invasive and prone to involve bone (ribs and scapula), invading the retroperitoneal space and spreading to lymph nodes, adrenals, and liver ${ }^{[3]}$ and usually present with common respiratory symptoms. In our case, lower ribs were also involved but responded to chemotherapy very well and no involvement was found peroperatively. Treatment is actually multimodal including chemotherapy, surgery and radiotherapy. Venkitaraman et al. proposed remarkable remission rate from $26 \%$ to $65 \%$ after chemotherapy. Most commonly used chemotherapy regimens include vincristine, actinomycin D and cyclophosphamide (VAC), VAC adriamycin (VACA) and VAC alternating IE (ifosfamide and etoposide). ${ }^{[8]}$ The regimen used by our oncology team was vincristine, ifosfamide, doxorubicin and etoposide and the patient responded well. The next important role to improve survival is complete surgical excision of tumour, though approach needs modification regarding exact location of tumour. In this case, the surgeon approached the residual tumour through transdiaphragmatic route. The extension of the tumour at diagnosis is the factor affecting prognosis although $70 \%$ of 5 -year survival is documented in literature. ${ }^{[9]}$

ES is usually sensitive to radiotherapy but needs to categorise the patient as far as selection is concerned, especially in case of younger age patient. ${ }^{[10]}$

No metastasis or relapse was seen in index case after successful excision and chemotherapy so radiotherapy was not given. The most common complications which can occur are in the form of relapses and musculoskeletal abnormalities, fortunately, both of which were not present in our case, as tumour proved out to be chemosensitive and great reduction in size was there which was easy to excise without any thoracic wall deformity. 


\section{Conclusion}

Askin's tumour is very rare in childhood. The most common presentation is with respiratory symptoms. High index of suspicion is required to diagnose it.

\section{Conflict of Interest}

The authors declare that they have no conflict of interest.

\section{References}

1. Sikri V, Sobti S. Askin tumour: A rare thoracopulmonary tumour in adults. Indian J Chest Dis Allied Sci 2013;55:233-5.

2. Pizzo PA, Poplack DG. Principles and Practice of Pediatric Oncology: $5^{\text {th }}$ ed. Philadelphia, PA: Lippincott Williams and Wilkins; 2006.

3. Askin FB, Rosal J, Sibley RK, et al. Malignant small cell tumour of the thoracopulmonary region in childhood: A distinctive clinicopathologic entity of uncertain histogenesis. Cancer 1979;43:2438-51.

4. Batsakis JG, Mackay B, el-Naggar AK. Ewing's sarcoma and peripheral primitive neuroectodermal tumour: An interim report. Ann Otol Rhinol Laryngol 1996;105:838-43.

5. Windfuhr JP. Primitive neuroectodermal tumour of the head and neck: Incidence, diagnosis, and management. Ann Otol Rhinol Laryngol 2004;113:533-43.

6. Brasme JF, Chalumeau M, Oberlin O, et al. Time to diagnosis of ewing tumours in children and adolescents is not associated with metastasis or survival: A prospective multicenter study of 436 patients. J Clin Oncol 2014;32:1935-40.

7. Aggarwal M, Lakhhar B, Aggarwal BK, et al. Askin's tumour: A malignant small cell tumour. Indian J Pediatr 2000;67:853-5.

8. Venkitaraman R, George MK, Ramanan SG, et al. A singular institution experience of combined modality management of extraskeletal Ewing's sarcoma. World J Surg Oncol 2007;11:5-13.

9. Imbach P, Kuhne T, Arcerci R. Pediatric Oncolgy-A Comprehensive Guide. $1^{\text {st }}$ ed. New York: Springer; 2006.

10. Parikh M, Samujh R, Kanojia RP, et al. Peripheral primitive neuroectodermal tumor of the chest wall in childhood: Clinico-pathological significance, management and literature review. Chang Gung Med J 2011;34:213-7. 